\title{
Highly sensitive electrochemical impedance spectroscopy based sensor for Staphylococcus aureus detection
}

\author{
Peng Gu ${ }^{1 \#}$, Jing Huang ${ }^{2 \#}$, Jiajiu Yao ${ }^{3 *}$ \\ ${ }^{1}$ General Hospital of the Yangtze River Shipping, Wuhan, Hubei, 430014, China \\ ${ }^{2}$ The Attached Hospital of Northeast Teachers University, Changchun, Jilin, 134000, China \\ ${ }^{3}$ Emergency Department, Tangdu Hospital, Air Force Military Medical University, Xi'an, Shaanxi \\ 710038, China \\ *E-mail: jiajiuyao_air@sina.com
}

Received: 3 August 2021 / Accepted: 18 September 2021 / Published: 10 November 2021

\begin{abstract}
Staphylococcus aureus is now considered one of the major pathogen of prostatitis. Its resistance to multiple drugs makes it difficult to treat, leading to a high morbidity and mortality rate. Therefore, it is imperative to establish sensitive, rapid and timely methods for the detection of Staphylococcus aureus. In this work, an electrochemical impedance spectroscopy sensor based on functionalized gold nanoparticles was constructed and realized for the rapid and highly sensitive analysis as well as the detection of Staphylococcus aureus. The experimental results demonstrated that the biosensor has a detection limit of $3 \times 10^{3} \mathrm{CFU} / \mathrm{mL}$ and a linear response range of $3 \times 10^{3}-3 \times 10^{7} \mathrm{CFU} / \mathrm{mL}$, which means a high sensitivity. In addition, the sensor has a short detection time, simple operation and high stability, which can be used for real-time detection.
\end{abstract}

Keywords: Staphylococcus aureus; EIS; Biosensor; AuNPs; Prostatitis

\section{$\underline{\text { FULL TEXT }}$}

(C) 2021 The Authors. Published by ESG (www.electrochemsci.org). This article is an open access article distributed under the terms and conditions of the Creative Commons Attribution license (http://creativecommons.org/licenses/by/4.0/). 